\title{
FINITE ELEMENT EVALUATION OF HUMAN BODY RESPONSE TO VERTICAL IMPULSE LOADING
}

\author{
Mahi Suresh ${ }^{1}$, Feng Zhu ${ }^{1}$, King H. Yang ${ }^{1}$, Jennifer L. Serres ${ }^{2}$, and Rabih E. Tannous ${ }^{2}$ \\ ${ }^{1}$ Bioengineering Center, Wayne State University \\ ${ }^{2}$ BAE Systems Land \& Armaments/Global Tactical Systems
}

\begin{abstract}
Vertical drop tests are commonly used to evaluate the effectiveness of energy absorbing seats in the mitigation of loads resulting from axial impulsive impacts. Crashworthy seats, designed to mitigate energy produced by landmine blast events against tactical vehicles, are often investigated and evaluated with the use of an Anthropometric Test Device (ATD) such as the Hybrid III dummy. Since these ATDs were originally designed to evaluate occupant response in frontal collisions, this paper presents a finite element analysis comparing the response of a Hybrid III dummy model to a human body model, newly modified at Wayne State University, in a vertical loading scenario. Two different seated configurations with varying leg angles for each model were vertically loaded with an acceleration pulse of $120 \mathrm{~g}$ for $10 \mathrm{~ms}$. The predicted responses from the two models were compared in terms of the forces and bending moments on the tibia and femur. It has been found that the responses predicted by both models exhibited similar trends, but compared to the Hybrid III dummy model, the forces and moments simulated with the human model gave lower peak values for longer durations.
\end{abstract}

\section{Keywords: Human Finite Element modelling; blast injuries; lower limb; drop tower test}

\section{INTRODUCTION}

Computational models of the human body and human surrogates have been utilized in various applications to evaluate the dynamic response of the human to various loads. A particular area of interest in recent years has been the use of these models in predicting lower extremity injuries, which are a major concern for mounted troops during an underbody blast event. During a blast event, pressure waves are produced and interact with the floor of the vehicle to cause the vehicle underbody and floor to accelerate upward. Although a large number of studies have reported on lower extremity injury in vehicles, most of them are focused on the frontal/side impact loading conditions relevant to the automotive industry. These studies provided useful information about the behavior of the lower extremities under these load conditions, but their results cannot be directly applied to a vertical loading condition. In the crash scenario, the average peak acceleration observed is usually around $40 \mathrm{~g}$ (Owen, 2001) and the average duration is from 15 to $45 \mathrm{~ms}$ whereas in case of blast events, the acceleration can be higher than $100 \mathrm{~g}$ with the duration lower than $10 \mathrm{~ms}$ (Wang et al., 2001).

A number of researchers have used various Anthropometric Test Devices (ATD) to study the biomechanical response of the lower limb by measuring the axial tibia force under axial load conditions (Wang et al., 2001; Pandelani et al., 2010). The major disadvantage of these surrogates is the lack of biofidelity to mimic the dynamic response of the human body. Although ATDs have 
been used extensively in automotive industry, their performance in vertical loading scenarios still requires additional calibration and validation.

Limitations also exist in the use of human cadavers. The cadaver testing results can be highly scattered since the responses of cadavers significantly vary depending on age and gender. In addition, it has been observed that embalmed cadaver specimens have a lower fracture tolerance than un-embalmed cadaver specimens (Kuppa et al., 2001). Moreover, due to the high cost and risk of conducting blast experiments, current interest in academia and government has turned to the numerical simulations by using finite element models (Quenneville et al., 2011; Horst et al., 2004). The current study proposes to use a newly developed Wayne State University Human Model (WSUHM) to study the response of the human body to a vertical impulse in two different seated postures with a primary focus on the response of the lower extremities. Time histories of the femur and tibia forces and bending moments are evaluated. Then, a comparative study was conducted to compare the behavior of the WSUHM and a commonly-used Hybrid III FE model.

\section{METHODOLOGY}

The aim of the current study is to simulate the response of the human under vertical, impulsive loading using FE models (WSUHM and Hybrid III $50^{\text {th }}$ percentile dummy model for comparison purpose). The responses of interest include tibia axial forces, femur shear force and bending moment. A drop tower system was used to simulate the vertical loading condition. The seated human body model together with the seat and foot plate is raised to a pre-determined height and then released. After the foot plate hits the floor, a deceleration pulse is generated and transmitted to the body. Figure 1 shows the initial position of the model setup in a drop tower test. The locations where the responses are monitored are also illustrated.

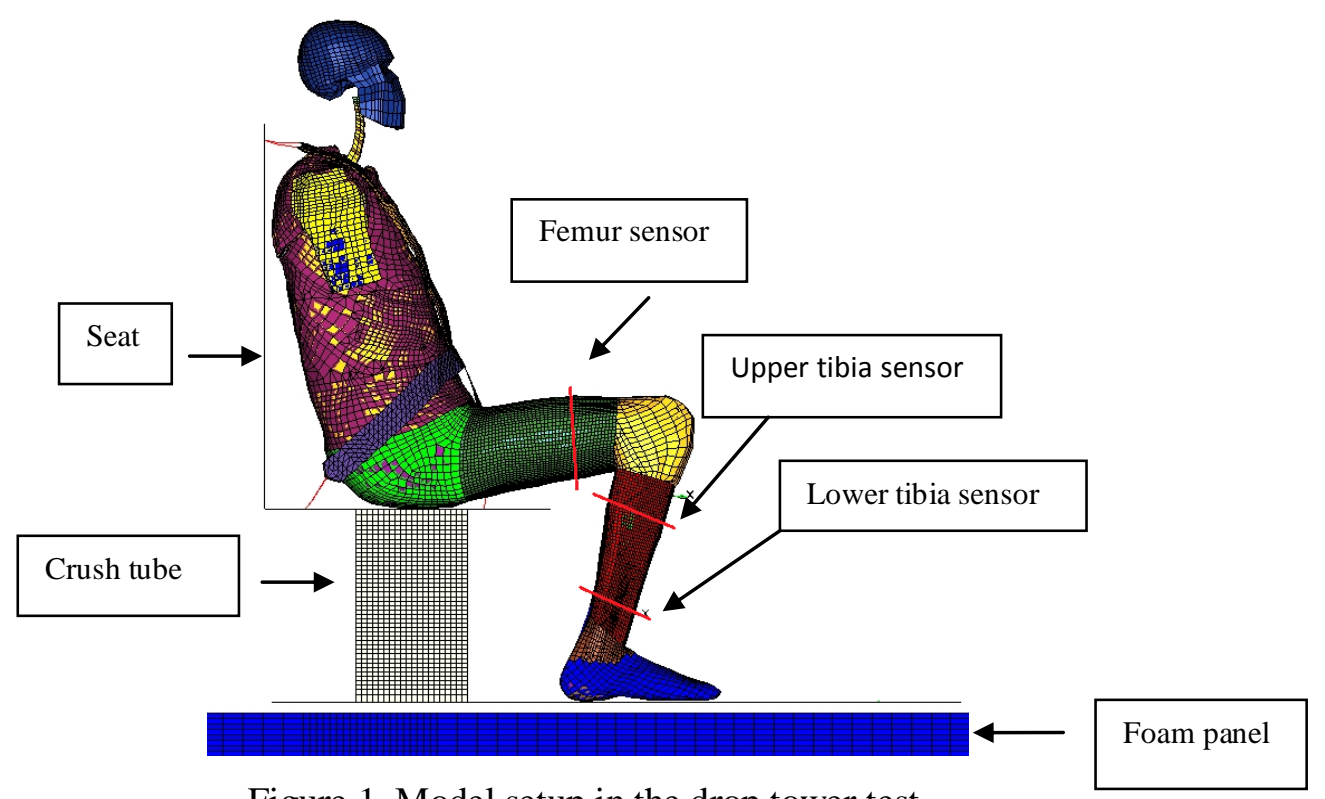

Figure 1. Model setup in the drop tower test. 
The WSUHM model is placed on a rigid seat which is connected to a rigid foot floor via a deformable, elastic crush tube, which allows proper energy transfer to the human model. The complete model (except foam panel) is given an initial velocity in the vertical direction to drop on the foam panel. The peak value and duration of the acceleration pulse applied to the foot plate were adjusted to $120 \mathrm{~g}$ and $5 \mathrm{~ms}$, respectively, by controlling the stiffness of the foam panel. Gravity was applied to all the parts. The human body was constrained with a five-point seat belt and configured in two postures, as shown in Figure 2.
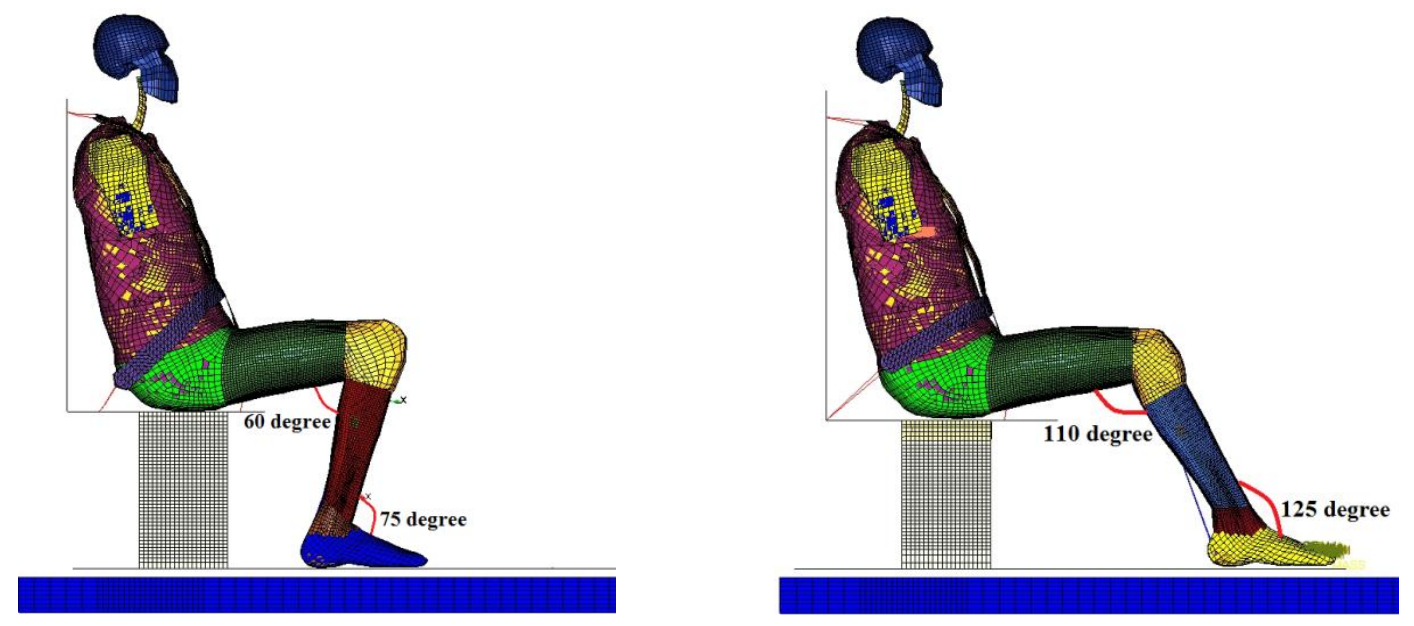

Figure 2. Two different configuration posture 1 (left figure) and posture 2 (right figure).

\section{NUMERICAL MODELS}

In this section, the development procedure of the WSUHM, as well as its material properties, are outlined. For comparison purposes, a Hybrid III FE model is also included and reviewed. The WSUHM was built with Hypermesh v10.0 (Altair Co. Troy, MI) and ANSYS ICEM v12.1 (ANSYS, Pittsburgh, Pennsylvania), and the dynamic simulations were performed using LSDYNA 971 (Livermore Technology Software Corporation (LSTC), Livermore, CA) MPP version.

\subsection{Hybrid III model}

Figure 3 shows the $50^{\text {th }}$ percentile Hybrid III dummy model developed by LSTC. This model is semi-deformable and the material for the tibia and femur was defined in LS-DYNA by a linear elastic material model with a Young's modulus of $200 \mathrm{GPa}$. 

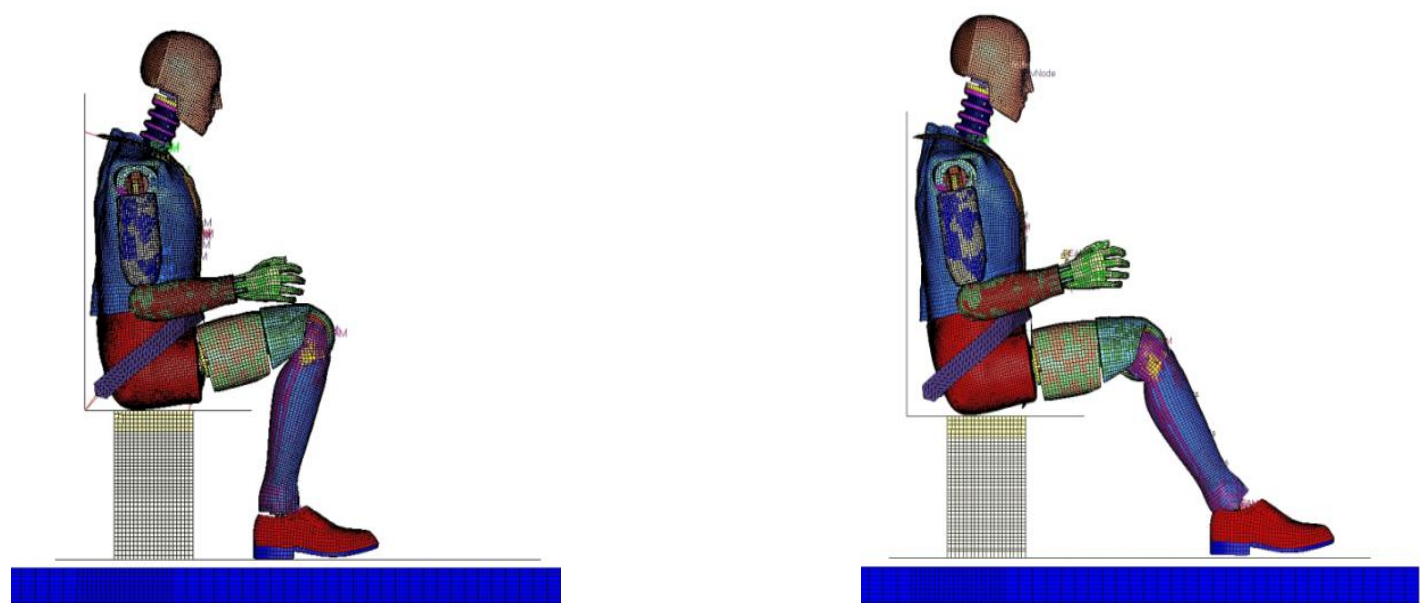

Figure 3. Hybrid III dummy FE model with two different configurations: posture 1 (left figure) and posture 2 (right figure).

\subsection{WSU Human Model}

The WSUHM is a newly developed full human body model. The lower limbs of the model were meshed using ANSYS-ICEM with a block meshing technique; with an average element size of $3 \mathrm{~mm}$. The cortical bone and trabecular bone were modelled with shell elements and solid elements, respectively. The femur and tibia muscles were modelled as solid elements. The knee joint ligaments were modelled as shell elements to connect bones and allow the bones to move and rotate. Figure 4 shows the mesh for the lower limb, with the enlarged view at the knee and ankle joints.

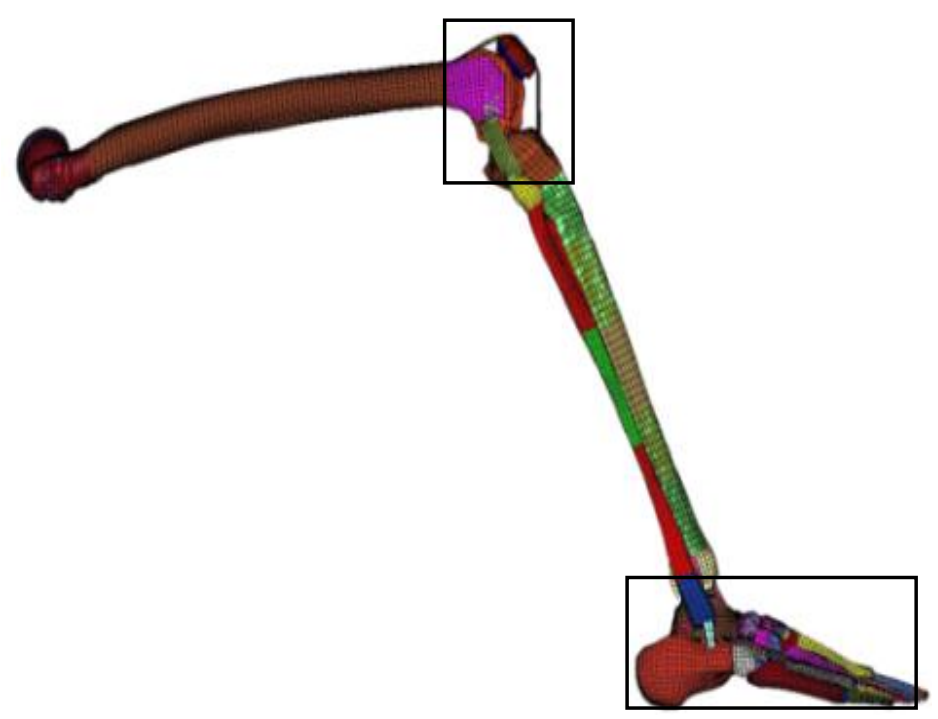

(a) Lower limb 


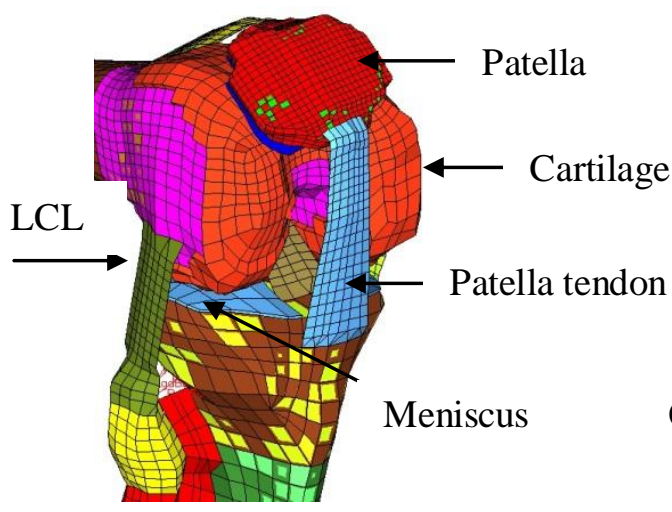

(b) Knee joint (enlarged view)

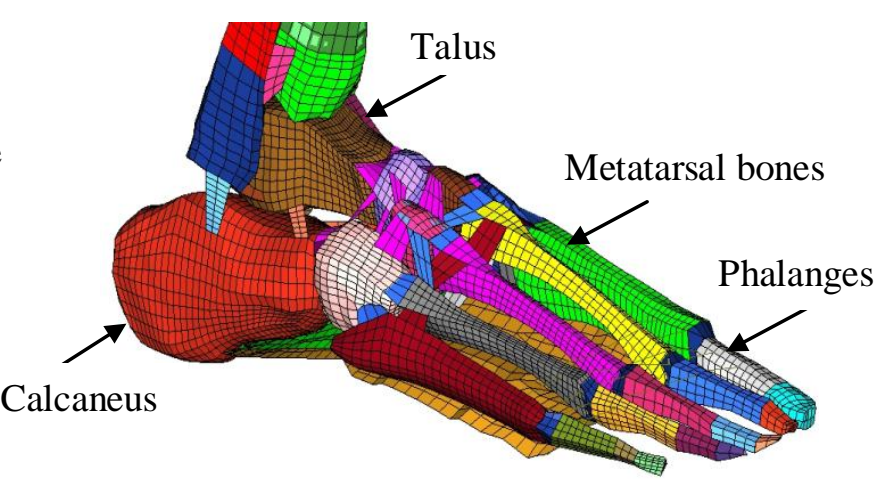

(c) Ankle joint (enlarged view)

Figure 4. The FE mesh of the WSUHM lower leg with the enlarged view of knee joint and ankle joint.

\subsection{Material Properties}

The material properties were primarily obtained from the literature. The cortical bone and trabecular bone of the femur and tibia were modelled using an elasto-plastic material law. The strain rate effects using the Cowper-Symonds model were included only for the cortical bone. Ligaments and tendons of the knee and ankle joints, menisci, and cartilage were modelled as elastic material. It was shown by Eberhardt et al. 1990, that the cartilage and menisci can be modelled as elastic material for the short duration loading because there is no time for the fluid within the cartilage to flow. The tibia and femur muscles were defined with a visco-elastic material, and the skin was defined using an elasto-plastic material constitutive relation. Table 1 lists the material properties for the main components of the leg model.

Table 1: Material properties for the main components of the models

\begin{tabular}{|c|c|c|c|c|c|c|}
\hline Parts & $\begin{array}{c}\text { Density } \\
\mathrm{kg} / \mathrm{m}^{3}\end{array}$ & $\begin{array}{c}\text { Young's } \\
\text { modulus } \\
(\mathrm{GPa})\end{array}$ & $\begin{array}{c}\text { Poisson's } \\
\text { ratio }\end{array}$ & $\begin{array}{c}\text { Yield } \\
\text { stress } \\
(\mathrm{GPa})\end{array}$ & $\begin{array}{c}\text { Tangent } \\
\text { modulus } \\
(\mathrm{GPa})\end{array}$ & References \\
\hline $\begin{array}{c}\text { Femur } \\
\text { cortical }\end{array}$ & $2.0 \times 10^{3}$ & 14 & 0.3 & 0.12 & 6.4 & McElhaney 1966 \\
\hline $\begin{array}{c}\text { Tibia } \\
\text { cortical }\end{array}$ & $1.85 \times 10^{3}$ & 16 & 0.3 & 0.13 & 1.0 & $\begin{array}{c}\text { Tannous et al., 1996; } \\
\text { Beaugonin et al., } \\
\text { 1997; } \\
\text { Burstein et al., 1976; } \\
\text { Untaroiu et al., 2005 }\end{array}$ \\
\hline $\begin{array}{c}\text { Femur } \\
\text { and tibia } \\
\text { trabecular }\end{array}$ & $1.0 \times 10^{3}$ & 0.45 & 0.3 & 0.01 & 0.025 & $\begin{array}{c}\text { Beaugonin et al., } \\
1997 ; \text { Kim et al., 2005 }\end{array}$ \\
\hline $\begin{array}{c}\text { Femur } \\
\text { head }\end{array}$ & $1.0 \times 10^{3}$ & 0.02 & 0.4 & - & - & Yamada et al., 1997 \\
\hline
\end{tabular}




\begin{tabular}{|c|c|c|c|c|c|c|}
\hline cartilage & & & & & & Beillas et al., 2001 \\
\hline Meniscus & $1.5 \times 10^{3}$ & 0.25 & 0.3 & - & - & Fithian et al., 1990 \\
\hline MCL & $1.0 \times 10^{3}$ & 0.25 & 0.46 & - & - & Robbin et al., 2001 \\
\hline LCL & $1.0 \times 10^{3}$ & 0.40 & 0.46 & - & - & Robbin et al., 2001 \\
\hline PCL & $1.0 \times 10^{3}$ & 0.2 & 0.46 & - & - & Robbin et al., 2001 \\
\hline ACL & $1.0 \times 10^{3}$ & 0.30 & 0.46 & - & - & Robbin et al., 2001 \\
\hline
\end{tabular}

\section{RESULTS AND DISCUSSION}

The responses from the Hybrid III and WSUHM FE models are compared in Figures 5-8 in terms of time history plots of femur shear force, femur bending moment and axial forces at lower and upper tibia. The exact senor locations can be seen in Figure 1, and the simulation results are summarized in Table 2. From the results, it can be observed that the force/moment time histories of the Hybrid III FE model had a higher peak value with a shorter duration compared to those from the WSUHM. This is due to the stiff material used in the Hybrid III leg. Significant overpredication of the responses based on the Hybrid III FE model indicates that commonly used engineering materials in the ATDs cannot mimic the behavior of the human body in the current loading scenario.

Apart from the discrepancy in peak values and durations, multiple peaks can be observed in the WSUHM plots. These oscillations may be caused by the joints where the bones are connected through ligaments and muscles. At different time intervals, the ligaments and muscles may switch between tension and compression states and move in the lateral direction, which then results in the significant change of the sign and magnitude of the force/moment curves. The HYBRID III leg, on the other hand, consists of a metallic shaft that articulates at the knee joint with a pin joint and at the ankle joint with a rigid ball joint. Since only rigid rotations and translations in a plane are allowed, the curves are much smoother. Similar findings have been observed by Bir et al. (2008) in their physical tests.

In both FE models, the response from posture 1 had higher peak values than posture 2, except for the upper tibia axial force. In the case of posture 1, the vertical force component experienced by the tibia is higher compared to posture 2 . But in the case of posture 2 , the vertical and horizontal force components acting on the tibia are larger because of the higher femur-tibia extension-flexion angle. 


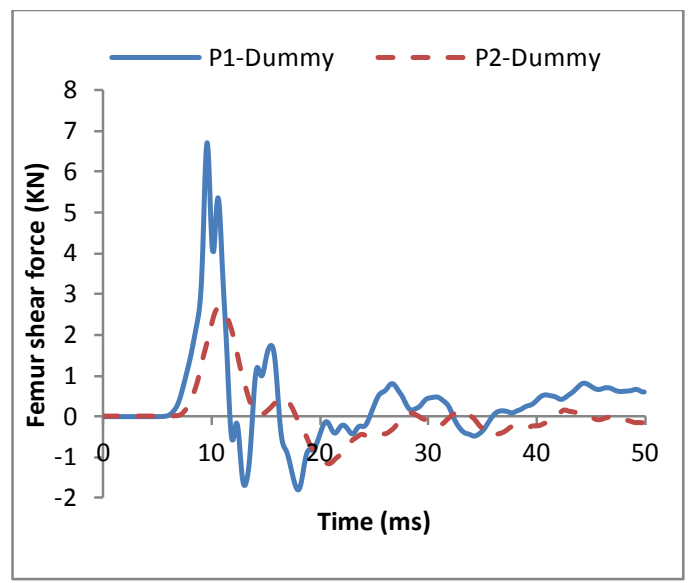

(a) Femur shear force-time history for Hybrid III

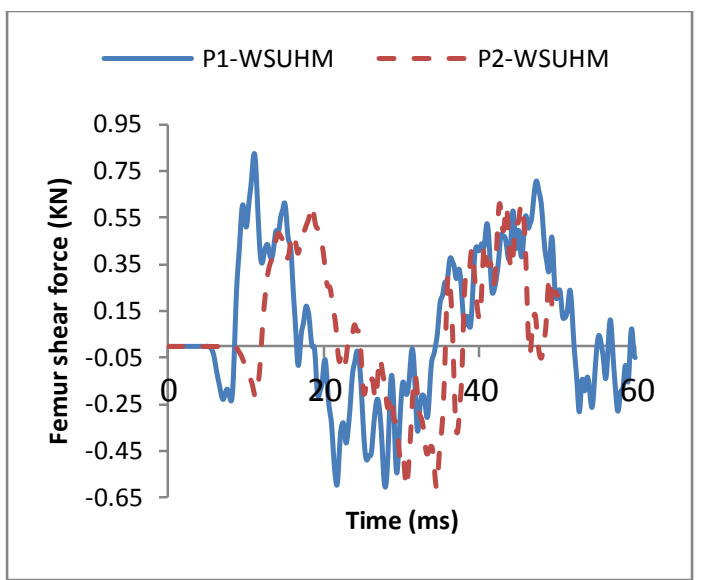

(b)Femur shear force-time history for WSUHM

Figure 5. Predicted shear force - time histories at the femur

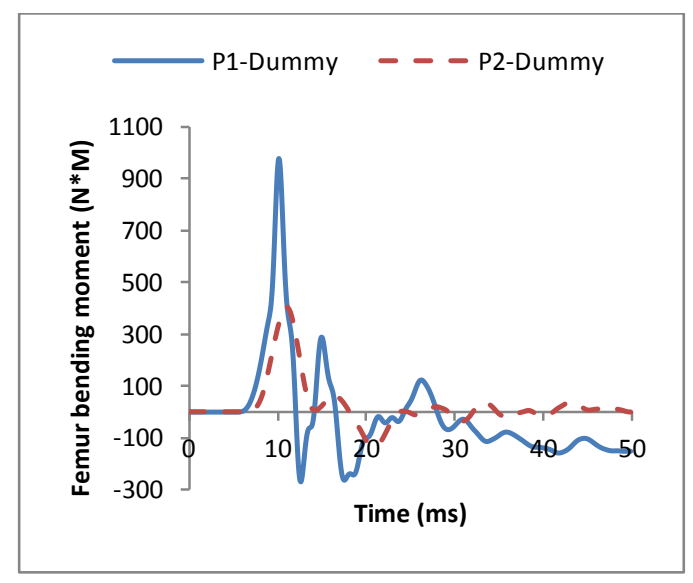

(a)Femur bending moment-time history for Hybrid III

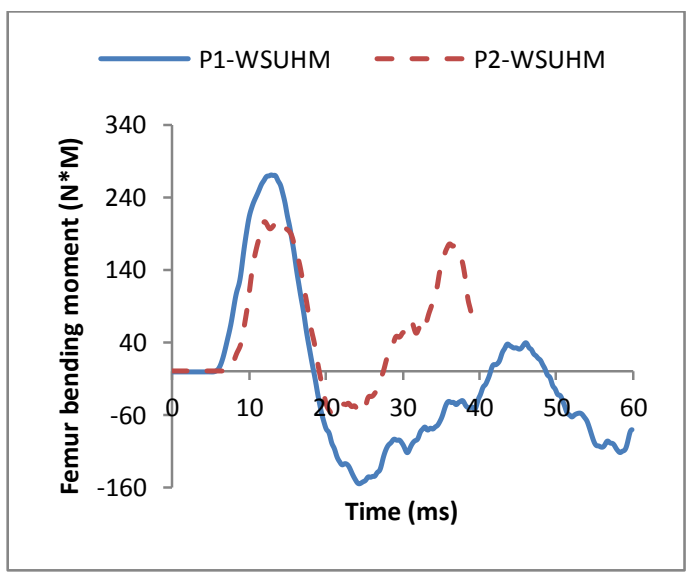

(b)Femur bending moment-time history for WSUHM

Figure 6. Predicted bending moment-time histories at the femur

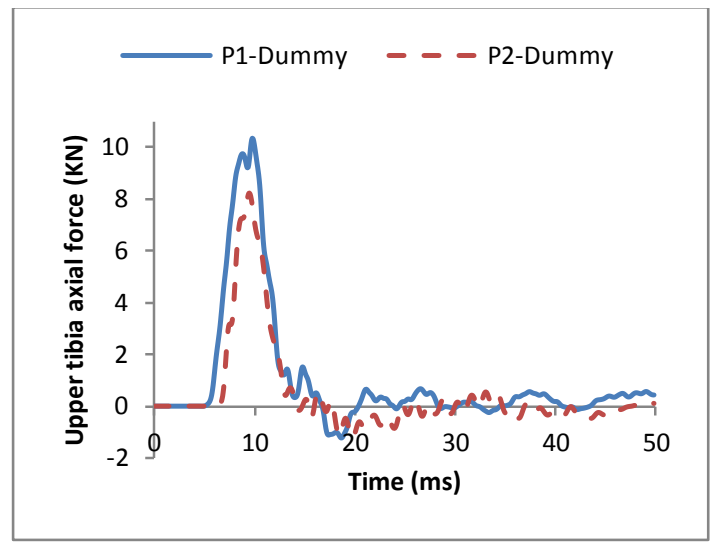

(a) Upper tibia axial force-time history for Hybrid III

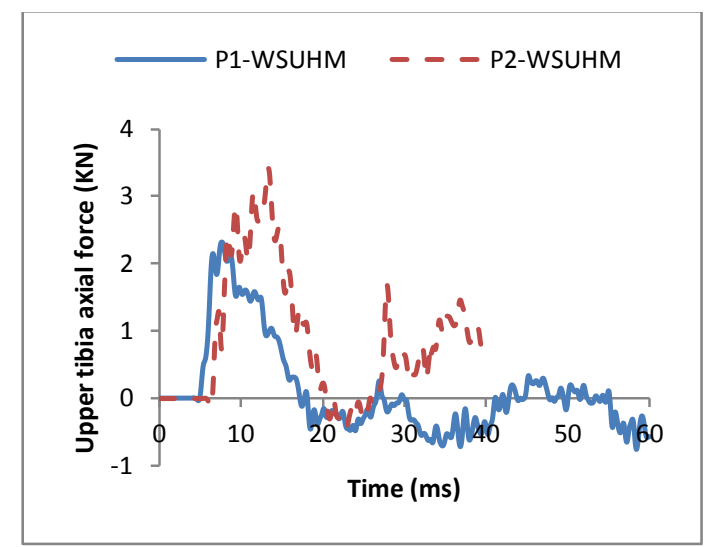

(b) Upper tibia axial force -time history for WSUHM

Figure 7. Predicted axial force-time histories at the upper tibia 


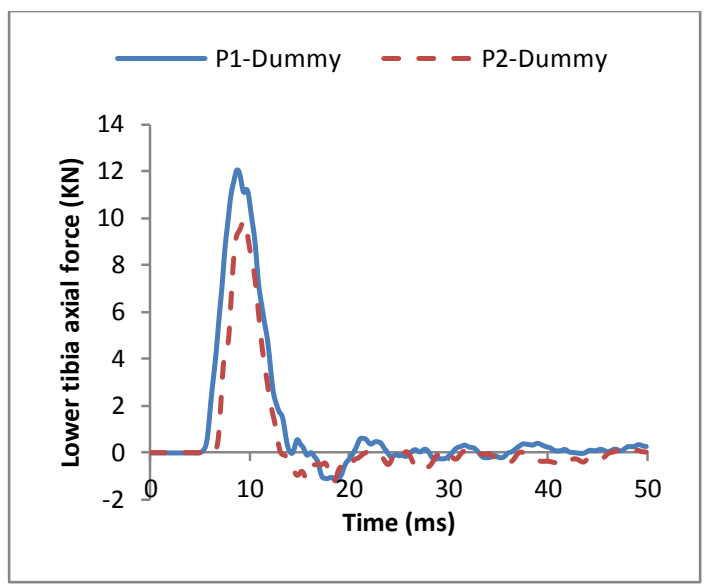

(a) Lower tibia axial force-time history for Hybrid III

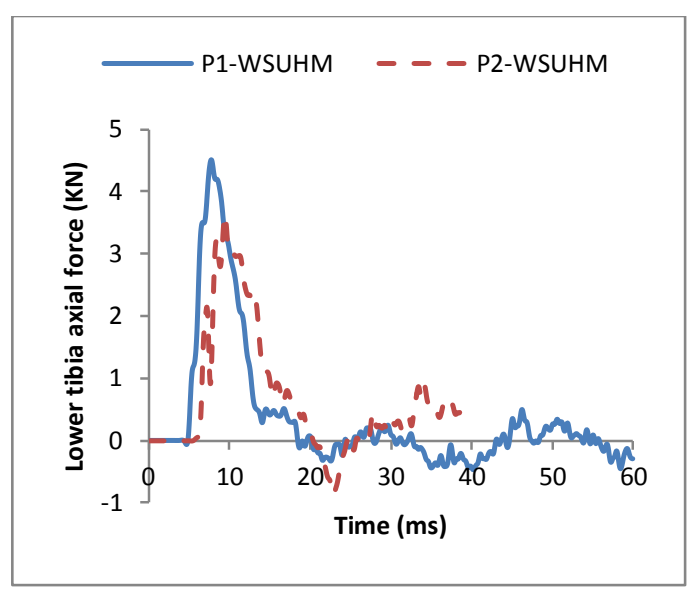

(a)Lower tibia axial force -time history for WSUHM

Figure 8. Predicted axial force-time histories at the lower tibia

Table 2: Summary of the peak values for the Hybrid III and WSUHM model

\begin{tabular}{|c|c|c|c|c|c|}
\hline \multirow{2}{*}{$\begin{array}{c}\text { Body } \\
\text { parts }\end{array}$} & \multirow{2}{*}{ Parameter } & \multicolumn{2}{|c|}{ Hybrid III } & \multicolumn{2}{c|}{ WSUHM } \\
\cline { 3 - 6 } Femur & $\begin{array}{c}\text { Femur shear force } \\
(\mathrm{N})\end{array}$ & 6711.6 & 2661.4 & 936.3 & 667.0 \\
\cline { 2 - 5 } & $\begin{array}{c}\text { Femur bending } \\
\text { moment (N*m) }\end{array}$ & 976.3 & 406.2 & 271.0 & 207.0 \\
\hline $\begin{array}{c}\text { Tibia } \\
\text { upper }\end{array}$ & $\begin{array}{c}\text { Upper tibia axial } \\
\text { force (N) }\end{array}$ & 10325.0 & 8217.4 & 2317.6 & 3423.3 \\
\hline $\begin{array}{c}\text { Tibia } \\
\text { lower }\end{array}$ & $\begin{array}{c}\text { Lower tibia axial } \\
\text { force (N) }\end{array}$ & 12058.0 & 9887.8 & 4504.8 & 3882.4 \\
\hline
\end{tabular}

\section{CONCLUSION}

A new finite element lower limb model was developed and integrated with the full body FE model WSUHM. The new model has sufficiently detailed anatomic structures and an average mesh size of $3 \mathrm{~mm}$. Numerical simulations were conducted to evaluate the response of the WSUHM and a Hybrid III FE model under impulsive vertical loading for two different seated positions. Both models predicted higher femur shear forces and higher axial forces in the lower tibia in posture 1 compared to posture 2. Additionally, the Hybrid III model yielded higher peak measurements with shorter durations compared to the WSUHM model. It was also noticed that multi-peaks occurred within the WSUHM simulation resulting from the complex nature of the 
human joint. Future applications of this work include the use of this model to study the response of a vehicle occupant to a vertical loading representative of an underbody blast event.

\section{Acknowledgments}

The authors acknowledge the support of BAE systems Land \& Armaments/Global Tactical Systems.

\section{REFERENCES}

[1] Owens B.D., Kragh J.F., Macaitis J., Svoboda S.J., and Wenke, J.C., 2007. "Characterization of extremity wounds in operation Iraqi freedom and operation enduring freedom". Journal of Orthopedic Trauma, 21, 254-257.

[2] Wang J., Bird B., Swinton B., and Krstic A. , 2001. "Protection of lower limbs against floor impact in Army vehicles experiencing landmine explosion. J Battlefield Technol.

[3] Kuppa S., Wang J. and Haffner M., 2001. "Lower extremity injuries and associated injury criteria", Proc. $17^{\text {th }}$ International Tech. Conference. Enhanced Safety of Vehicles, National Highway Traffic Safety Administration, Amsterdam, Netherlands.

[4] Bir C., Barbir B., Dosquet F., Wilhelm M., Horst M., Wolfe G., 2008. "Validation of lower limb surrogates as injury assessment tools in floor impacts due to anti-vehicular land mines". Association of Military Surgeons of the U.S.

[5] Nilakantan G. and Tabiei A., 2009. "Computational assessment of occupant injury caused by mine blasts underneath infantry vehicles”, Int. J. Vehicle Structures and Systems.

[6] Rayeesa A., Reinecke D., Snyman I., Whyte T., 2010. "The design and implementation of a lower leg impact tester to assist in lower limb injury criteria research". Science real and relevant conference 2010.

[7] Pandelani T., Reinecke D., Beetge F., 2010. "In pursuit of vehicle landmine occupant protection: Evaluating the dynamic response characteristic of the military lower extremity leg (MiL-Lx) compared to the hybrid III lower leg". Science real and relevant conference 2010.

[8] Quenneville CE., McLachlin S., Fraser GS., Dunning CE., 2010. "Injury tolerance criteria for short-duration impulse loading of the isolated tibia". The journal of Trauma injury, Infection and Critical care, volume 70 .

[9] Tannous RE., Bandak FA., Toridis TG., Eppinger R., 1996. "A three dimensional finite element model of the human ankle: development and preliminary application to axial implusive loading". Society of Automotive engineers, Inc., Warrendale, PA, USA. 
[10] Beaugonin M., Haug E., Cesari D., 1997. "Improvement of numerical ankle/foot model:modeling of deformable bone". Stapp Car crash J.41:224-237.

[11] Brustein AH., Reilly DT., Martens M., 1976. “Aging of bone tissue: mechanical properties. J bone joint surg (Am volume). 58:82-86.

[12] Untaroiu C., Darvish K., Crandall J., Deng B., Wang JT., 2005. "A finite element models of the lower limb for simulation pedestrian impacts". Stapp Car crash J.49:157-181.

[13] Kim YS., Choi HH., Cho YN., Park TJ., LEE JB., Yang KH., King AI., 2005. "Numerical investigation of interactions between the knee-thigh-hip complex with vehicle interior structures". Stapp Car crash J.49:85-115.

[14] McElhaney J.H., 1966. "Dynamic response of bone and muscle tissue". Journal of Applied Physiology, 21. 